$\omega_{0}$ is the threshold for interband absorption, with a final state consisting of a plasmon and an electron-hole pair. This fits the position of the peak, but Hermanson's calculation of the strength of this plasmon side-band effect concludes that its intensity should be about an order of magnitude less than that observed in caesium. Other explanations for this effect must therefore be sought.

It is worth noting that the study of optical properties of alkali metals is fraught with experimental difficulties associated with the difficulties of producing and maintaining clean flat surfaces on these extremely reactive metals. It has in the past proved very difficult for different laboratories using slightly different techniques to obtain concordant results, and here too it would be valuable to have the results confirmed by a different technique.

\section{CYCLIC AMP}

\section{Omnipotent Nucleotide}

from our Cell Biology Correspondent

THESE days cell biologists seem to be attracted to neuroblastoma cells almost as inevitably as iron filings are drawn to a magnet, for neuroblastoma cells can be maintained in culture, they can be induced to differentiate into nervelike cells with compounds such as dibutyryl cyclic AMP ( $\mathrm{Bu}_{2}$-cAMP) and they are, moreover, malignant. In short, cultivated neuroblastoma cells provide an in vitro experimental system with which such fashionable problems as the molecular basis of differentiation and malignancy and the role of cyclic AMP in the regulation of cell division can be explored; and the ripe and the not so ripe fruits of such labours are appearing with regularity in the literature. Waymire, Weiner and Prasad, for example, have recently reported (Proc. US Nat. Acad. Sci., 69, 2241 ; 1972) measurements of the changes in the activity of tyrosine hydroxylase in cultures of neuroblastoma cells after exposure to $\mathrm{Bu}_{2}-\mathrm{cAMP}$, to other substituted cAMPs, to papaverine, an inhibitor of cyclic nucleotide diesterase, and to sodium butyrate. Tyrosine hydroxylase is believed to catalyse the rate-limiting step in the synthesis of catecholamines in neuroblastoma cells, and it is therefore a biochemical marker of a differentiated function of these cells.

Waymire et al. find that when neuroblastoma cells are explanted and placed in primary cultures the tyrosine hydroxylase activity progressively decreases as the culture ages so that after 7 days the activity is only 2 per cent that of freshly explanted cells. When, however, $\mathrm{Bu}_{2}$-cAMP is added at concen-

trations which Hsie and Prasad have shown induce the formation of axonlike processes, not only do the cells undergo this morphological differentiation but also the activity of tyrosine

\title{
Palaeocirculation in Antarctic Waters
}

ONE of the less familiar consequences of continental drift and seafloor spreading is the change in oceanic circulation patterns brought about by the contraction and expansion of oceans. The Antarctic circumpolar current, for example, is the largest volume flow in the world and, as its name implies, now runs between Antarctica and Australia along part of its route. Clearly, however, this could not have been the case before the separation of the two continents, which began during the early Eocene and must have produced drastic changes in circulation that could well have influenced the erosion of the deep ocean floor.

In next Monday's Noture Physical Science (September 25) Kennett et al. report evidence of such erosion during the early Oligocene, based on an analysis of cores obtained from the Tasman and Coral Seas during Leg 21 of the Deep Sea Drilling Project (see map). The essential discovery involved is that of a regional unconformity which is present in both ridge and basin areas at present water depths of 1,400 to $4,600 \mathrm{~m}$. In principle, such an unconformity could have been caused by slumping, but this is usually relatively local unless induced by tectonism; and hydroxylase increases dramatically. But addition of sodium butyrate, a potential breakdown product of $\mathrm{Bu}_{2}$ cAMP, also causes a considerable increase in the tyrosine hydroxylase ac-

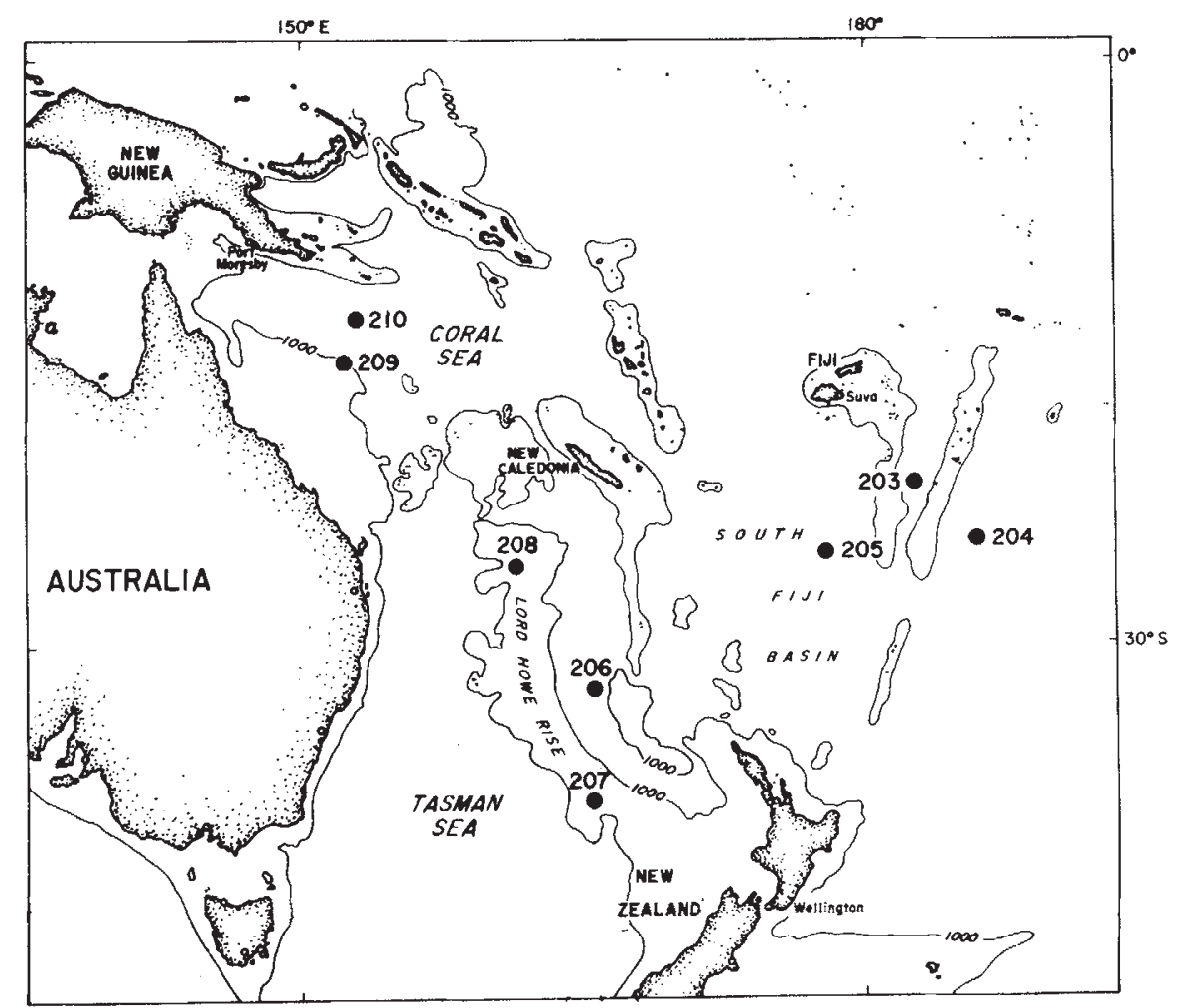

most of the tectonism in the area is known to have occurred before the late Eocene. Kennett and his colleagues thus conclude that the unconformity must be explained in terms of erosion effects by particularly vigorous bottom waters.

There is now plenty of evidence to suggest that ancient oceanic circulation patterns are greatly influenced by the glacial history of Antarctica, with intensified circulation occurring during glacial episodes. One of the principal Cainozoic glacial episodes is known to have occurred during the period from late Eocene to early Oligocene ; and so it is likely that the chief cause of the erosional unconformity is glacial. At the same time, however, the location of the erosion-and in this case its wide extent-is almost certainly influenced by plate tectonic configurations and their changes. Bearing this in mind, Kennett et al. then go on to describe three possible detailed hypotheses which can explain the widespread unconformity in terms of the glacial and tectonic behaviour in the area and which are consistent with observation. At present, the most valid of the three circulationerosion histories cannot be distinguished from the others. 